\title{
HUBUNGAN BUDAYA LITERASI (BACA-TULIS) DENGAN HASIL BELAJAR BAHASA INDONESIA SISWA KELAS XI SMA NEGERI 7 DENPASAR
}

\author{
Pt Melia Suandewi, Ida Bagus Putrayasa, Gede Gunatama \\ Program Studi Pendidikan Bahasa Indonesia Fakultas Bahasa dan Seni \\ Universitas Pendidikan Ganesha \\ e-mail\{meliaawandewi@gmail.com ${ }^{1}$,ibputra@gmail.com ${ }^{2}$ detama_fbs_21@yahoo.com $\left.{ }^{3}\right\}$
}

\begin{abstract}
ABSTRAK
Penelitian ini bertujuan untuk mengetahui hubungan budaya literasi (baca-tulis) dengan hasil belajar bahasa Indonesia siawa kelas XI SMA Negeri 7 Denpasar. Penelitian ini merupakan penelitian koreleasional. Populasi dalam penelitian ini adalah siswa kelas XI SMA Negeri 7 Denpasar sedangkan sampel dalam penelitian ini siswa kelas XI IPA 4, XI IPA 6, XI IPA 10, dan XI IPS 1. Teknik pengambilan sampel yang digunakan ialah teknik random sampling. Metode pengumpulan datadalam penelitian ini adalah metode observasi, tes, dan dokumentasi. Data yang terkumpul dianalisis dengan analisis deskriptif dan analisis regresi satu predictor. Hasil penelitian ini menunjukkan bahwa (1) budaya literasi siswa kelas XI SMA Negeri 7 termasuk ke dalam kategori sangat tinggi dengan nilai rata - rata budaya literasi 82,78. (2) hasil belajar Bahasa Indonesia siswa kelas XI SMA Negeri 7 juga termasuk ke dalam kategori sangat tinggi dengan nilai rata - rata 78,78. (3) Terdapat hubungan positif dan signifikan antara budaya literasi dengan hasil belajar Bahasa Indonesia siswa kelas XI SMA Negeri 7 Denpasar dengan beta pisitif 0,843. Hal ini berarti semakin meningakat budaya literasi akan semakin meningkatkan hasil belajar Bahasa Indonesia sebesar 0,843 , sebaliknya jika budaya literasi semakin menurun maka hasil belajar Bahasa Indonesia akan semakin menurun sebesar 0,843.
\end{abstract}

Kata kunci : Budaya Literasi, hasil belajar bahasa Indonesia

\begin{abstract}
This research aims to determine the relationship between literacy culture (reading-writing) and the result of learning Indonesian of XI grade students of Senior High School number 7 Denpasar. This research was corelational research. The population in this research were XI grade students of Senior High School number 7 Denpasar while the sample in this research were students of class XI IPA 4, XI IPA 6, XI IPA 10, and XI IPS 1. The technique which was used in taking the sample was random sampling technique. The method which was used in collecting the data was observation, testing, and documentation. The collected data was analyzed by descriptive analysis and regression analysis of one predictor. The results of this research indicate that (1) the literacy culture of XI grade students of Senior High School number 7 falls into a very high category with an average literacy culture value of 82.78. (2) the result of learning Indonesian language of XI grade students of Senior High Scholl number 7 also belong to a very high category with an average score of 78.78 . (3) There was a positive and significant relationship between literacy culture and the result of learning Indonesian language of XI grade students of Senior High School number 7 Denpasar with a positive beta of 0.843 . It means that the more literacy culture will increase the Indonesian Language learning by 0.843 , whereas if the literacy culture has decreased, the result of Indonesian language learning will decrease by 0.843 .
\end{abstract}

Keywords: Literacy Culture, the results of learning Indonesian 


\section{Pendahuluan}

Dalam dunia pendidikan, literasi disebut dengan gerakan literasi sekolah (GLS). Gerakan literasi sekolah ini bertujuan untuk meningkatkan literasi pada siswa. Sejalan dengan hal tersebut, Dirjen Pendidikan Menengah (2016) menyatakan bahwa gerakan literasi sekolah (GLS) merupakan suatu usaha atau kegiatan yang bersifat partisipatif dengan melibatkan warga sekolah (kepala sekolah, guru, siswa, pengawas sekolah, komute, dan orang tua siswa)

Literasi menjadi sarana bagi siswa untuk mengenal, memahami, dan menerapkan ilmu pengetahuan yang dimilikinya agar berkembang secara optimal.Penerapan literasi di sekolah bertujuan untuk mengembangkan potensi siswa yang meliputi kecerdasan intelektual, emosional, bahasa, spiritual, estetika yang beradaptasi dengan perkembangan teknologi dan informasi. Secara umum "upaya yang dilakukan sekolah untuk meingkatkan kemampuan literasi para siswa yaitu mengadakan pembiasaan melalui pengembangan atau penciptaan budaya literasi dan pembiasaan di kelas disetiap mata pelajaran" (Subandiyah, 2015).

Kemampuan literasi $\begin{array}{r}\text { dapat } \\ \text { diperoleh dari }\end{array}$
pembelajaran.Literasi pada dasarnya
merupakan aktivitas membaca dan
menulis. Menurut Tarigan (dalam Zaini,

2018:29) terdapat lima alasan literasi lebih diarahkan pada kemampuan membaca dan menulis. Pertama, pembaca adalah pembangun makna, setiap pembaca memiliki tujuan membaca.Tujuan tersebut menggerakkan pikirannya tentang topik dan mengaktifkan hubungan pengetahuan latar belakangnya. Sama halnya pembaca, penulis juga bertindak melalui proses yang mirip dengan pembaca. Penulis juga memiliki tujuan untuk menulis dan menggerakkan pikirannya tentang topik yang ingin ditulis dan akan mengaktifkan pengetahuan latar belakangnya sebelum menulis. Kedua, membaca dan menulis merupakan pengetahun dan proses yang sama. Membaca dan menulis saling berbagi proses pengetahuan yang sama. Pengetahuan yang dihasilkan dalam menulis merupakan hasil dari proses membaca. Ketiga, pembelajaran membaca dan menulis dapat meningkatkan prestasi.Berdasarkan tinjauan peneliatan tentang pengaruh membaca dan menulis, disimpulkan bahwa menulis menggiring pada peningkatan prestasi membaca, membaca menggiring pada kemampuan menulis yang lebih baik.Kombinasi pembelajaran keduannya menggiring pada peningkatan kemampuan membaca dan menulis.Keempat, membaca dan menulis dapat membantu perkembangan komunikasi.Membaca dan menulis bukan hanya keterampilan yang harus dipelajari 
untuk mendapatkan nilai belajar yang baik tapi juga proses membaca dan menulis tersebut membantu siswa berkomunikasi secara efektif.Kelima, kombinasi membaca dan menulis mengajak siswa untuk berpikir tingkat tinggi.Suatu elemen penting dalam pembelajaran literasi secara umum ialah berpikir, dalam kombinasi pembelajaran membaca dan menulis menuntut siswa untuk berpikir kritis dan/atau tingkat tinggi.

Pentingnya kemampuan membaca dalam kehidupan menuntut siswa untuk miningkatkan minat bacanya.Karena, melalui kegiatan membaca siswa dapat mengali informasi dan ilmu pengetahuan yang tersimpan di dalam buku-buku dan media tulis lainnya.Membaca adalahsalah ativitas dalam kegitan literasi yang merupakan kunci bagi kemajuan pendidikan. la jendela bagi masuknya ilmu pengetahuan. Sudiana (2007: 2) mengatakan membaca dapat diibaratkan sebagai kunci pembuka gudang ilmu pengetahuan. Dengan demikian, melalui membaca wawasan yang dimiliki siswa niscaya akan bertambah.

Namun, sebagian masyarakat Indonesia belum menyadari banyaknya manfaat membaca dan menulis. Oleh sebab itu, tingkat kemampuan membaca dan menulis masyarakat masih tergolong rendah dibandingkan dengan negaranegara lain. Hal tersebut dibuktikkan dari hasil penelitian PISA (Programme for International Student Assesment)tahun
2009 menyatakan bahwa hasil literasi siswa di Indonesia berada pada peringkat ke-57 dengan skor 396 (dengan skor ratarata OECD 493), sedangkan hasil penelitan PISA tahun 2012 menunjukkan pada peringkat ke-64 dengan skor 396 (dengan skor rata-rata OECD 496) dan hasil penelitian terbaru PISA pada tahun 2015 menunjukan hasil yang sama dengan tahun 2012 (Wahyuni, 2018). Terkait hal tersebut, hasil studi Most Littered Nation in the World yang dilakukan oleh Central Connecticut State Univesity (dalam Kurniawan, 2017) pada maret 2016 lalu yang menyatakan bahwa Indonesia menduduki peringkat ke-60 dari 61 negara mengenai minat membaca dan menulis. Kemampuan membaca dan menulis tersebut diartikan dengan istilah literasi.

Penyebab rendahnya literasi atau kemampuan membaca dan menulis siswa disebabkan oleh sifat manja dan/atau malas siswa untuk menulis dan membaca.Rendahnya kemampuan membaca dan menulis siswa berpengaruh terhadap hasil belajar siswa di sekolah.Kegiatan literasi (baca-tulis) memiliki peranan besar dalam pembelajaran.Widnyana mengemukakan "Keberhasilan peserta didik dalam memperoleh hasil belajar juga berawal dari kegiatan literasi. Senada dengan hal tersebut, Ferrandino dan Gerald Tirozzi (dalam isi halaman Schmoker, 2012) mengatakan bahwa 
Volume : 9 Nomor: 2, Agustus 2019

P-ISSN : 2614-4743 (cetak) dan e-ISSN : 2614-2007 (online)

kemampuan literasi yang kurang berkembang menjadi alasan utama siswa tinggal kelas, dipindahkan ke pendidikan khusus, diberikan layanan perbaikan jangka panjang, dan tidak lulus SMA. Pendapat yang sama juga dikemukakan oleh Schmoker (2012:64) "membaca dan menulis jika dikombinasikan, memberikan kontribusi luar biasa terhadap kecerdasan kritis". Dengan demikian kemampuan literasi sangatlah penting bagi siswa untuk meraih keberhasilan hasil belajar.

Selain untuk memperoleh hasil belajar yang baik, pembelajaran literasi (baca-tulis) dapat membantu peserta didik memahami dan menemukan strategi yang efektif untuk kemampuan membaca dan menulis, sehingga membaca dan menulis menjadi hal yang menyenangkan bagi siswa.

Literasi (baca-tulis) erat kaitannya dengan mata pelajaran bahasa Indonesia, seperti yang dipaparkan di atas bahwa kemampuan literasi merupakan bagian dari kemampuan berbahasa. Oleh sebab itu hasil belajar bahasa Indonesia berpengaruh terhadap kemampuan literasi siswa. Literasi dalam pembelajaran bahasa merupakan dua hal yang saling berkaitan. Menurt Abidin, dkk (2017), Penelitian telah menunjukkan bahwa kemampuan berbahasa anak memengaruhi keterampilan literasinya secara signifikan. Guru Bahasa Indonesia berperan penting dalam mengembangkan dan mengajarkan kemampuan literasi demi tercapanya hasil belajar yang maksimal.

Berbicara mengenai literasi, SMA Negeri 7 Denpasar telah melaksanakan gerakan literasi sekolah.Gerakan literasi sekolah ini sudah menjadi kebudayaan (kebiasaan) siswa/siswi SMA Negeri 7 Denpasar.Kegiatan literasi yang dilaksanakan di SMA Negeri 7 Denpasar sudah pada tahapan pengembangan.Menurut salah satu guru bahasa Indonesia di SMA Negeri 7 Denpasar,Luh Putu Adhi Laksmini Susila mengakatan di tahun 2016 ke bawah hasil belajar bahasa Indonesia siswa/siswi SMA 7 Denpasar setiap tahunnya tidak mengalami peningkatan secara drastis. Sedangkan di tahun 2018, hingga sekarang siswa SMA Negeri 7 Denpasar memang menunjukkan peningkatan hasil belajar bahasa Indonesia.Dengan demikian peneliti menyimpulkan bahwa peningkatan hasil belajar erat kaitannya dengan budaya literasi yang diterapkan di sekolah tersebut sejak tahun 2017. Berdasarkan hal tersebut, peneliti merasa penting melakukan penelitian mengenai hubungan budaya literasi (baca-tulis) dengan hasil belajar bahasa inonesia siswa.

\section{Metode Penelitian}

Rancangan penelitian yang digunakan dalam penelitian ini adalah rancangan korelasional.Rancangan korelasional yang digunakan bertujuan 
untuk mengetahui hubungan antara literasi baca-tulis dengan hasil belajar bahasa Indonesia siswa SMA Negeri 7 Denpasar. Tempat dilaksanakannya penelitian ini yakni di SMA Negeri 7 Denpasar pada kelas XI tahun ajaran $2018 / 2019$. Populasi dalam penelitian ini adalah seluruh siswa kelas XI SMA Negeri 7 Denpasar tahun pelajaran 2018/2019 yang terdiri dari 12 kelas..Teknik pengambilan sampel pada penelitian ini yaitu random sampling.Dipilihnya teknik random sampling karena sifat populasi begitu homogen dan paralel.

Pengumpulan data dapat dilakukan dengan berbagai setting, berbagai sumber dan berbagai cara. Pada penelitian ini, penulis menggunakan 3 metode pengumpulan data, yaitu tes, observasi, dan dokumentasi. Metode tes digunakan untuk mengukur kemampuan literasi siswa. Dalam metode ini peneliti menyiapkan soal-soal tes yang berasal bari buku-buku bacaan literasi siswa. Metode observasi digunakan untuk mengetahui pelaksanaan budaya literasi di SMA Negeri 7 Denpasar.Metode observasi yang dilakukan berupa kegiatan observasi nonpartisipant artinya peneliti tidak ikut secara aktif dalam kegiatan literasi, tetapi peneliti mengamati dan melakukan pencatatan pelaksanaan literasidan situasi yang menyertainya. Metode dokumentasi digunakan untuk melihat hasil belajar atau hasil ulangan harian sebelum dilakukannya tes literasi.
Metode ini digunakan untuk mengukur hasil belajar bahasa Indonesia siswa.

Metode analisis data yang digunakan adalah analisis deskriptif dan analisis regeri satu prediktor. Aanalisis deskriptif digunakan untuk menggambarkan hasil belajar siswa dan kemampuan literasi siswa. analisis regresi satu prediktor digunakan untuk menentukan besarnya hubunngan satu prediktor terhadap kriterium dan menentukan regresi.

\section{Hasil dan Pembahasan}

Data tentang budaya literasi dengan jumlah siswa 144, diperoleh ratarata sebesar 82,78, median sebesar 85,00 , modus sebesar 85 , nilai maksimum 100 , nilai minimum 55 , rentangan 45, banyak kelas 8 , dan panjang kelas interval 6 . Untuk mengetahui kualitas variabel budaya literasi, nilai rata-rata budaya literasi dikonversikan kedalam kategori klasifikasi skala limapenilaian acuan ideal teoritik sehingga menghasilkan Tabel konversi seperti padatable berikut.

\begin{tabular}{|l|l|l|l|}
\hline No & Kriteria & Rentang & Klasifikasi \\
\hline 1 & $\mathrm{Mi}+1,5 \mathrm{SDi} \square \mathrm{M} \square \mathrm{Mi}+3,0 \mathrm{SDi}$ & $75 \square X$ & Sangat \\
\hline 2 & $\mathrm{Mi}+0,5 \mathrm{SDi} \mathrm{M}_{<} \mathrm{Mi}+1,5 \mathrm{SDi}$ & $58 \triangle X_{<} 75$ & Tinggi \\
\hline 3 & $\mathrm{Mi}-0,5 \mathrm{SDi} \mathrm{M}_{<} \mathrm{Mi}+0,5 \mathrm{SDi}$ & $42 \square X_{<} 58$ & Sedang \\
\hline 4 & $\mathrm{Mi}-1,5 \mathrm{SDi} \square \mathrm{M}_{<} \mathrm{Mi}-0,5 \mathrm{SDi}$ & $25 \square X_{<42}$ & Rendah \\
\hline 5 & $\mathrm{Mi}-3,0 \mathrm{SDi} \square \mathrm{M}_{<} \mathrm{Mi}-1,5 \mathrm{SDi}$ & $0 \quad X_{<25}$ & Sangat \\
\hline
\end{tabular}

Berdasarkan hasil konversi, diperoleh bahwa nilai rata-rata budaya literasi siswa kelasi XI SMA Negeri 7 
Denpasar tergolong ke dalam kriteria "Sangat Tinggi" dengan $\mathrm{M}=82,78$. Kriteria sangat tinggi yang di peroleh siswa dikarenakan oleh disiplinya siswa saat melaksanakan literasi dan dukungan eksternal lainnya seperti lingkungan sekolah dan sarana prasarana literasi.

Data tentang hasil belajar siswa pada mata pelajaran Bahasa Indonesia kelas XI SMA Negeri 7 Denpasar dengan jumlah siswa 144, diperoleh rata-rata sebesar 78,78, median sebesar 80,00, modus sebesar 75 , nilai maksimum 100 , nilai minimum 50 , rentangan 50 , banyak kelas 8, dan panjang kelas interval 7 . Berdasarkan data tersebut dapat dibentuk distribusi frekuensi nilai hasil belajar Bahasa Indonesia kelas XI SMA Negeri 7 Denpasar, seperti padaTabel berikut.

\begin{tabular}{|l|l|l|l|l|}
\hline No & Interval & Titik & Frekuensi & $\begin{array}{l}\text { Frekue } \\
\text { nsi } \\
\text { Komul } \\
\text { Absolute } \\
\text { (f) }\end{array}$ \\
\hline 1 & $50-67$ & 53 & 6 & 6 \\
\hline 2 & $57-72$ & 60 & 5 & 11 \\
\hline 3 & $64-77$ & 67 & 18 & 29 \\
\hline 4 & $71-82$ & 74 & 42 & 71 \\
\hline 5 & $78-87$ & 81 & 25 & 96 \\
\hline 6 & $85-92$ & 88 & 29 & 125 \\
\hline 7 & $92-98$ & 95 & 12 & 137 \\
\hline 8 & $\begin{array}{l}99 \\
105\end{array}$ & 102 & 7 & 144 \\
\hline & & & 144 & \\
\hline
\end{tabular}

Hasil penelitian ini menjukkan bahwa terdapat hubungan positif antara budaya literasi (baca-tulis) dengan hasil belajar bahasa Indonesia siswa kelas XI SMA Negeri 7 Denpasar. Semakin sering siswa melakukan literasi maka semakin menigkat pula hasil belajar siswa. Siswa yang sering melakukan kegiatan literasi (baca-tulis) niscaya akan memiliki wawasan dan pengatuhan yang lebih luas, semakin luas wawasan dan pengetahuan yang dimiliki siswa berpengaruh terhadap hasil belajarnya. Hal tersebut sejalan dengan pendapat Karl Popper (dalam Schmoker 2012:63) menyatakan bahwa membaca dan menulis merupakan peristiwa besar dalam perkembangan intelektual seseorang. Dengan demikian budaya literasi (baca-tulis) memiliki hubungan yang positif terhadap hasil belajar bahasa Indonesia siswa

Berdasarkan hasil penelitian yang dilakukan, SMA Negeri 7 Denpasar telah melaksanakan Gerakan Literasi Sekolah (GSL) sesuai dengan peraturan menteri pendidikan dan kebudayaan tahun 2015 meluncurkan suatu gerakan perubahan budaya baca + tulis yang bertajuk "Gerakan Literasi Sekolah" dengan tema "Bahasa penumbuh Budi Pekerti".

Berdasarkan hasil analisis, diperoleh nilai rata - rata budaya literasi siswa kelas XI SMA Negeri 7 Denpasar 82,78. Jika dikonversikan nilai rata - rata budaya literasi siswa kelas XI SMA Negeri 7 Denpasar termasuk ke dalam kategori sangat tinggi.Hal tersebut dapat dilihat dari hasil tes literasi yang dilakukan peneliti dan hasil observasi literasi yang 
dilakukan peneliti.Berdasarkan hasil tes siswa kelas XI SMA Negeri 7 Denpasar, nilai yang diperoleh rata-rata 80 ke atas sehingga dikatagorikan sangat tinggi.Pemerolehan hasil literasi yang tinggi juga dipengaruhi oleh kedisiplinan saat melaksanakan literasi (baca+tulis).senada dengan hal tersebut (UNESCO, 2003; dalam Kemendikbud, 2016) menegaskan namun, hal yang paling mendasar dalam praktik literasi adalah kegiatan membaca dan menulis.

Selain kedisiplinan dalam melaksanakan literasi, sarana-prasarana juga sangat mendukung dalam kegiatan literasi. Berdasarkan observasi yang dilakukan peneliti, sarana dan prasarana yang di sediakan di SMA Negeri 7 Denpasar sudah sangat lengkap mulai dari tersedianya buku-buku bacaan, perpustakaan mini di kelas, taman baca dan atau pojok baca, buku jurnal literasi, dan poster-poster ayo gemar membaca. dengan adanya sarana -prasarana tersebut akan menambah semangat siswa dalam melaksanakan literasi. Hal tersebut sesuai dengan Dirjen Pendidikan Menengah (2016) menyatakan bahwa, program gerakan literasi sekolah ini dilaksanakan secara bertahap dengan mempertimbangkan, kesiapan kapasitas sekolah (ketersediaan fasilitas, bahan bacaan, sarana prasarana literasi), kesiapan warga sekolah dan kesiapan pendukung lainnya.
Berdasarkan hasil analisis, diperoleh nilai rata - rata hasil belajar Bahasa Indonesia siswa kelas XI SMA Negeri 7 Denpasar 78,78. Jika dikonversikan nilai rata - rata hasil belajar Bahasa Indonesia siswa kelas XI SMA Negeri 7 Denpasar termasuk ke dalam kategori sangat tinggi. Hal tersebut menandakan bahwa siwa telah berhasil dan/atau mampu menguasai materi pelajaran di sekolah, sehingga hasil belajar bahasa Indonesia siswa kelas XI SMA Negeri 7 Denpasar termasuk ke dalam kategori sangat tinggi.

Sejalan dengan pendapat Sumartono (dalam Rahman, 2012:158) mengemukakan "hasil belajar adalah suatu nilai yang menunjukan hasil yang tertinggi dalam belajar yang dicapai menurut kemampuan anak dalam mengerjakan sesuatu pada saat tertentu". Senada dengan hal tersebut $\mathrm{K}$ Brahim (dalam Susanto, 2013:5) mengatakan "Hasil belajar dapat diartikan sebagai tingkat keberhasilan siswa dalam mempelajari materi pembelajaran di sekolah yang dinyatakan dalam skor yang diperoleh dari hasil tes".

Secara deskriptif budaya literasi memiliki rata - rata nilai yakni 82,78 yang digolongkan pada kategori sangat tinggi, dilihat dari hasil belajar Bahasa Indonesia, nilai rata - rata siswa sebesar 78,78 yang juga dikategorikan sangat tinggi sehingga budaya literasi kelas XI SMA Negeri 7 Denpasar dan hasil belajar Bahasa Indonesia kelas XI SMA Negeri 7 
Denpasar sama - sama dalam kategori sangat tinggi.

Berdasarkan analisis pengaruh dan hubungan antara budaya literasi dan hasil belajar Bahasa Indonesia, dapat dilihat bahwa budaya literasi berpengaruh terhadap hasil belajar Bahasa Indonesia siswa kelas XI SMA Negeri 7 Denpasar, hal ini dilihat dari nilai signifikan uji $F$ sebesar 0,000 kurang dari 0,05 $(0,000<$ $0,05)$ serta signifikan uji t 0,000 kurang dari 0,05 dengan beta positif 0,843 sehingga dapat disimpulkan bahwa terdapat hubungan yang positif dan signifikan antara budaya literasi baca-tulis dengan hasil belajar Bahasa Indonesia siswa kelas XI SMA Negeri 7 Denpasar dan pengaruh tersebut adalah positif, jadi semakin meningakat budaya literasi akan semakin meningkatkan hasil belajar Bahasa Indonesia sebesar 0,843, sebaliknya jika budaya literasi semakin menurun maka hasil belajar Bahasa Indonesia akan semakin menurun sebesar 0,843 .

Uji lain yang digunakan juga adalah uji korelasi atau uji hubungan antara budaya literasi baca-tulis dengan hasil belajar Bahasa Indonesia siswa kelas XI SMA Negeri 7 Denpasar yang memperoleh signifikan hasil 0,000 kurang dari $0,05(0,000<0,05)$ sehingga dapat pula disimpulkan terdapat hubungan yang positif dan signifikan antara budaya literasi baca-tulis dengan hasil belajar Bahasa Indonesia siswa kelas XI SMA Negeri 7
Denpasar. Koefisien yang diperoleh sebesar 0,644 adalah positif sehingga, hubungan antara budaya literasi baca-tulis dengan hasil belajar Bahasa Indonesia siswa kelas XI SMA Negeri 7 Denpasar adalah hubungan yang positif.

Hal senada diungkapkan oleh Risa Yanuarti Sholihah pada penelitiannya tahun 2016/2017 di SMA Negeri 2 malang, dari hasil penelitiannya, Risa menyimpulkan bahwa kemampuan literasi dasar siswa sebesar 78,3\% tergolong baik, prestasi belajar siswa sebesar 81,7 $\%$ tergolong baik dan terdapat hubungan positif antara kemampuan literasi dengan prestasi belajar siswa. Di pertegas pula dengan hasil penelitian yang dilakukan oleh Rahmi Nurfadhilah pada tahun 2012 yang menyebutkan "siswa yang literasinya baik prestasi belajarnya juga baik, begitu juga siswa yang literasinya semakin baik mereka mendapatkan hasil prestasi semakin baik dan rata-rata raport mereka mendapatkan hasil belajar di atas angka $80 "$

Berdasarkan dua paparan hasil penelitan diatas, jelas bahwa budaya literasi dan hasil belajar bahasa Indonesia siswa memiliki hubungan yang positif.

\section{Simpulan dan saran}

Berdasarkan hasil pengujian hipotesis dan pembahasan, maka dapat disimpulkan budaya literasi siswa kelas XI SMA Negeri 7 termasuk ke dalam kategori sangat tinggi dengan nilai rata - rata 
budaya literasi siswa kelas XI SMA Negeri

7 Denpasar 82,78. Hasil belajar Bahasa Indonesia siswa kelas XI SMA Negeri 7 termasuk ke dalam kategori sangat tinggi dengan nilai rata - rata hasil belajar Bahasa Indonesia kelas XI SMA Negeri 7 Denpasar 78,78. Hubungan yang positif dan signifikan juga terdapat antara budaya literasi baca-tulis dengan hasil belajar Bahasa Indonesia siswa kelas XI SMA Negeri 7 Denpasar.Dari hasil uji $F$ bahwa diperoleh nilai sig. sebesar $0,000<0,05$ serta nilai signifikan uji $t$ dan korelasi $0,000<0,05$ dengan beta positif 0,843.

Ada beberapa hal yang dapat peneliti sarankan. (1) Untuk meningkatkan hasil belajar siswa, guru hendaknya memerhatikan dan mengembangkan program literasi, karena program literasi memiliki andil besar terhadap hasil belajar siswa. (2) Seluruh siswa SMA Negeri 7 Denpasar khususnya kelas XI hendaknya selau semangat dalam mengikuti program literasi ini agar hasil belajarnya lebih meningkat. (3) Peneliti lain diharapkan untuk melakukan penelitian sejenis yang terkait dengan motivasi belajar dan kemampuan menulis siswa.

Pada mulanya program gerakan literasi sekolah yang dibuat pemerintah ini bertujuan untuk menumbuhkan budi pekerti siswa. Namun nyatanya literasi tidak hanya menumbuhkan budi pekerti, tetapi juga memiliki hubungan yang sejalan dengan hasil belajar siswa. Siswa yang memiliki hasil belajar yang baik pasti memiliki kemampuan literasi yang bagus. Namun, hal tersebut belum disadari penuh oleh pihak sekolah sehingga literasi belum menjadi hal yang diutamakan.

\section{Daftar Pustaka}

Kamendikbud. (2016). Desain Induk Gerakan Literasi Sekolah . Jakarta: Direktoral Jendral Pendidikan Dasar dan Menengah Kementrian Pendidikan dan Kebudayaan Republik Indonesia

Kurniawan, Komang Indra .(2017). Implementasi Program Gerakan Literasi (GIS) di SMA Negeri 1 Singaraja.Skripsi (tidak diterbitkan) Jurusan PBSI, Undiksha.

Rahmi Nurfadhilah. "Hubungan Kemampuan Literasi Informasi Anggota Ikatan Pustakawan pelajar dengan Prestasi Belajar di Sekolah".Jurnal Mahasiswa vol 1.No. 1. (2012)

Schmoker, M. (2012).Menjadi Guru yang Efektif; Bagaimana Mencapai Pembangunan Baru Melalui Membaca dan Menulis. Jakarta: Erlangga 
Volume : 9 Nomor: 2, Agustus 2019

P-ISSN : 2614-4743 (cetak) dan e-ISSN : 2614-2007 (online)

Subadiah, Heny. 2015. "Pembelajaran Literasi dalam Mata Pelajaran Bahasa Indonesia". http://ejournal.fbs.unesa.ac.id

Sudiana, I Nyoman.(2007). Membaca. Malang: Universitas Negeri Malang.

Susanto, Ahma. (2013). Teori Belajar dan Pembelajaran di Sekolah Dasar. Jakarta: Kencana Prenadamedia Group.

Wahyuni, dkk. 2018.“ PengaruhFull Day School dan Gerakan Literasi Sekolah terhadap Hasil Belajar dengan Mediasi Motivasi Belajar". Jurnal Pendidikan Online Vol. 3 No.5. (halm. 679684).

Widnyana. I Komang.(2018). Kemampuan Literasi Dalam Pembelajaran Bahasa Indonesia Berbasis Teks Pada Siswa Kelas VII SMP Negeri 2 Rendang.Skripsi (tidak diterbitkan) Jurusan PBSI, Undiksha.

Zaini, (2018). Program Literasi dalam Meningkatkan Prestasi Belajar Siswa (studi kasusnSMA ALMiftah Potoan Laok Palengaan Pamekasaan dan SMA Al-Aziz Tlambah Karangpenang Sampang). Tesis Pascasarjana Universitas Islam Negeri Sunan Ampel Surabaya. 